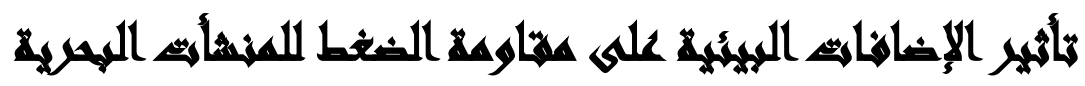 هيك الكرين
}

[?]

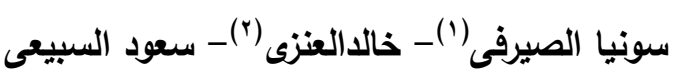

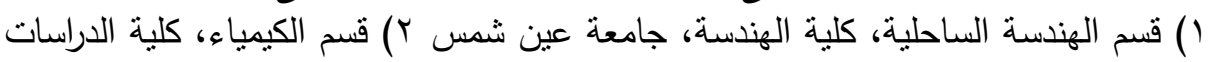

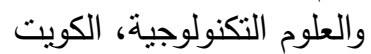

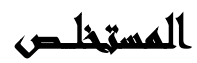

نظرا لأهمية المنشات البحرية فى دولة الكويت، بدأت هذه الدراسة بهدف زيادة مقاومتها

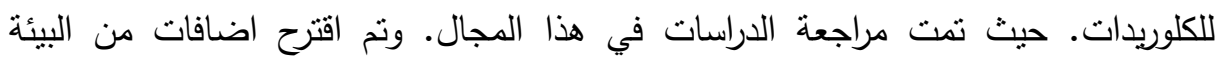

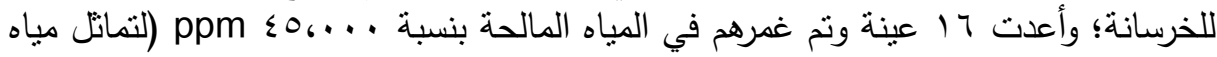

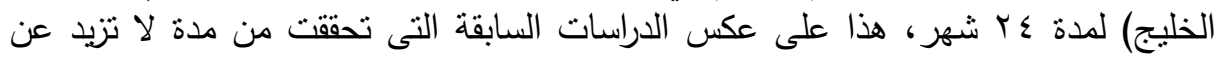

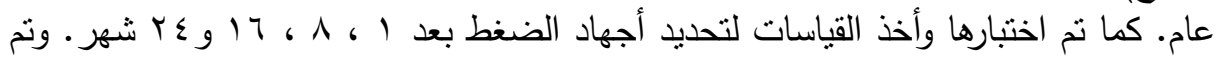

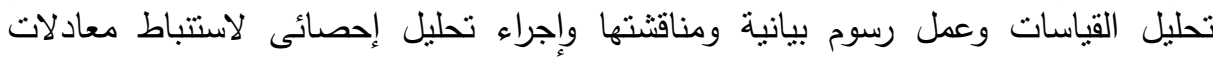

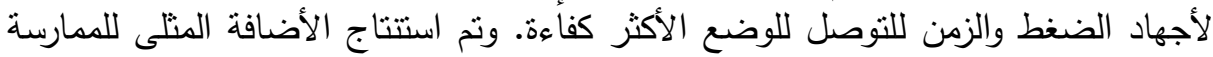

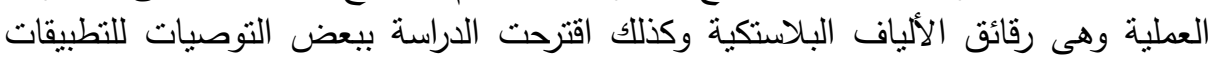

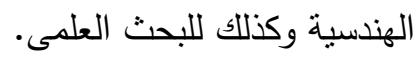
الكلمات المفتاحية: الإضافات البيئية، مقاومة الضغط، المنشأت البحرية، الكويت

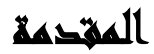

إن تآكل حديد التسليح هو السبب فى تدهور المنشآت الخرسانية الساحلية لارتفاع نفاذيتها وتسرب الأملاح والرطوبة. ولذا نم البدأ فى هذه الورقة البحثبة بهدف دهرب دراسة الجهاد

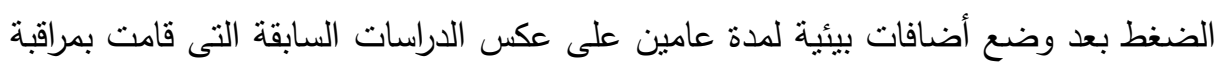
الخرسانة لمدة لا تزيد عن العام لأرتفاع تكلفة البحث واستنفاذ الوقت عدمان.

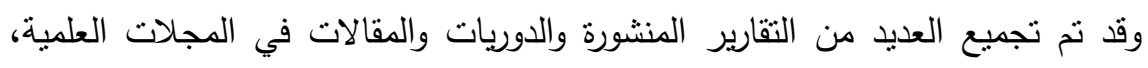
واستعراضها وتحليلها وقد وجدت أبحاث كثيرة فى هذا المجال. ومنها على سبيل المثال

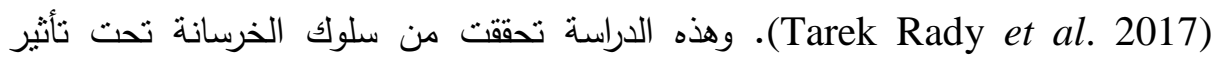
الكلوريدات بعد وضع أضافات وناقتت الدراسة كيفية زيادة عمر الهياكل البحرية الخرسانية

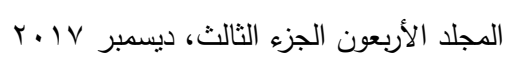


El-Serafy et al. فى الأراضى المنخفضة فى مصر (دلتا نهر النيل). كما أن الدراسة قامت بفحص خصائص الخرسانة للكلوريدات وهذه الدراسة تعتبر أحدى الدراسات في مجال حماية خرسانة المناطق الساحلية. وأيضا الدراسة (El-Serafy et al. (2017b) حيث نم فحص خصائص الخرسانة للكلوريدات فى الأنفاق وهذه الدراسة أيضا تعتبر أحدى الدراسات فى مجال حماية الأنفاق. وتقدم هذه الورقة النتائج والتوصيات بالأضافة الى أهداف الدراسة ومنهجيتها والدراسة المعلية والتحليلية.

\section{أمساهن الصراسمة}

المنشآت البحرية عمرها قصير لتعرضها لظروف بيئية قاسية فتتحلل وتتهار بعد فترة

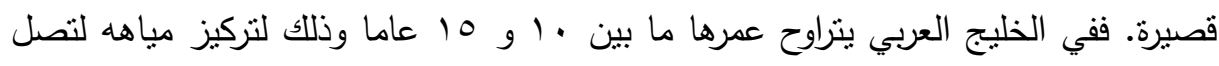

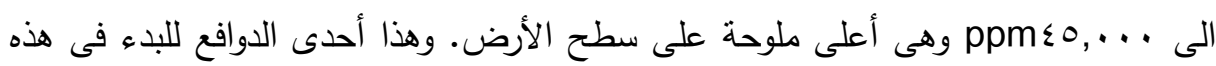

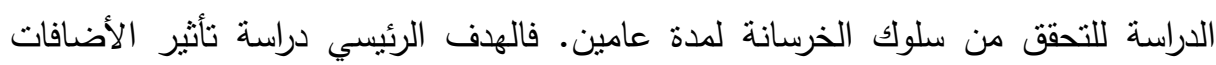
البيئية على مقاومة الضغط للمنثأت البحرية في دولة الكويت. والأهداف التبعية هى افتراح

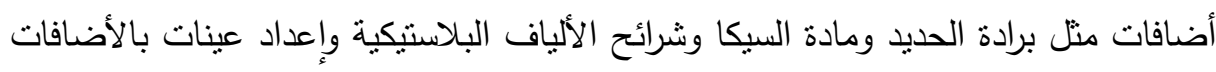

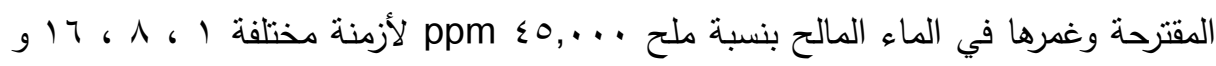

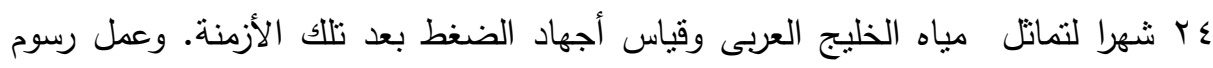
بيانية تربط مابين المتغيرات لتحديد كفاءة كل اضافة ثم تحليل النتائج ومناقثتها لأختيار

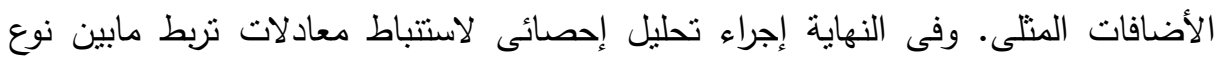
الأضافة والزمن وأجهاد الضغط. و الضاف.

\section{منهبيه الصراسلة}

وبالتعرف على الأهداف الدحددة للاراسة، تم تخطيط مراحل التحقيق البحثى أي المنهجية لتشمل المرحلة النظرية حيث يتم مراجعة الدراسات السابقة في مجال الخرسانة

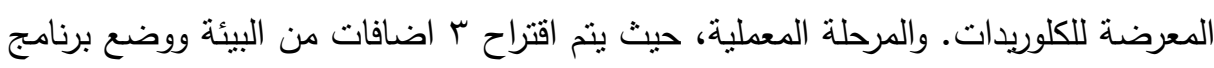


معملى، واعداد العينات وغمرها في المياه المالحة لمدة ؟r شهر واجراء القياسات لتحديد إجهاد الضغط، بعد 1، 1 ، 17 و ع ك شهر • والمرحلة التحليلية، حيث يتم تحليل القياسات وتوضيحها بالرسومات البيانية لتربط مابين المتغيرات وتتاقش النتائج ويتم اجراء تحليل احصائى لاستتباط معادلات مابين إجهاد الضغط والزمن ونوع الأضافة. أخيرا المرحلة الاستتناجية، حيث يتم استتناج كيفية نفيذ المعالجة الأكثر كفاءة في الممارسة العملية. وأعطاء توصيات لممارسة الهندية والبحث العلمى.

\section{الترواسة المعملية}

فقد تم تخطبط للبرنامج المعملى ليشمل الأختبار 17 عينة. تم تقسيمه إلى ع

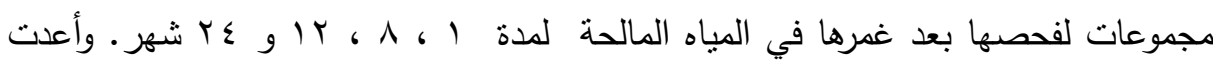

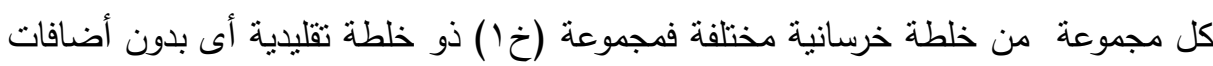

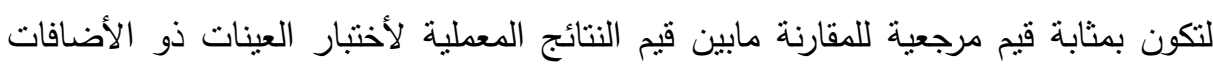

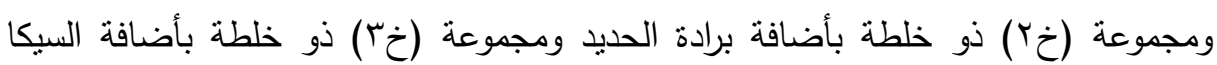
ومجموعة (خء) ذو خلطة بأضافة الرقائق البلاسنيكية. وكل المجموعات تم غمرها في المياه

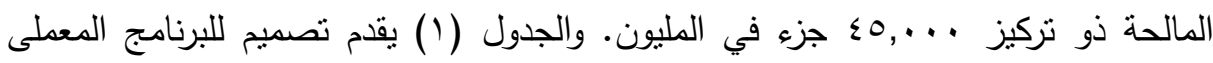

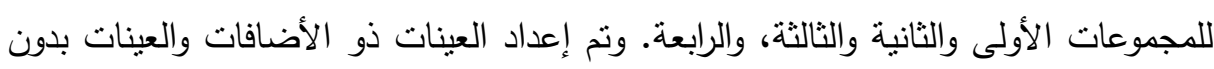

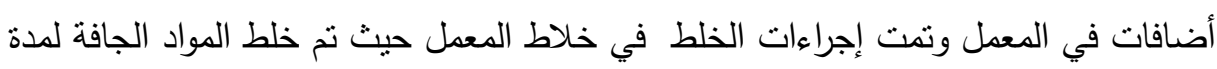

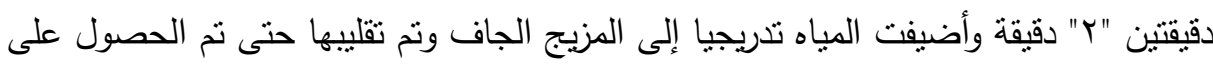

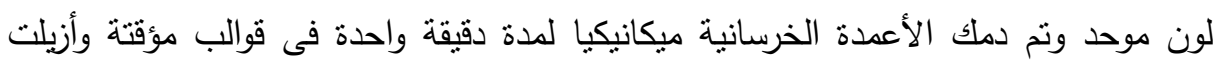

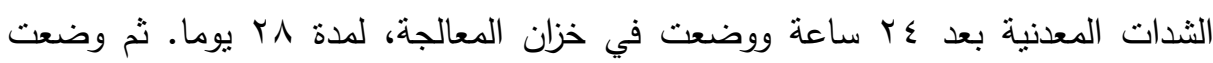

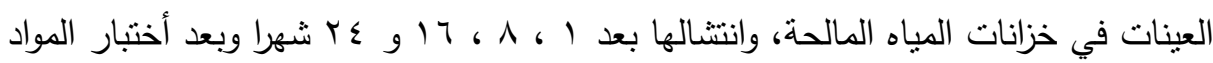

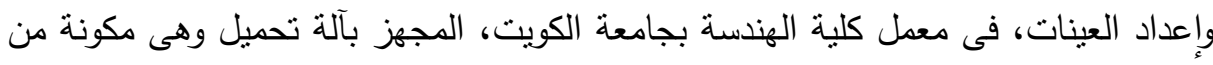
إطار التحميل وآلة تحميل هيدروليكية، وضعت في خزانات المياه المالحة. وبعدها تمت القياسات وحيث أن أجهاد الضغط يتأثر كثيرا فى الخرسانة المعرضة للكلوريدات لأنها نؤدي فئري

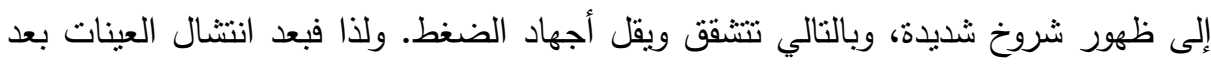

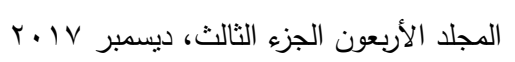


الفترة المحددة لها، طبقا للبرنامج المعلى، وضعت على إطار التحميل وتم تحميل العينات

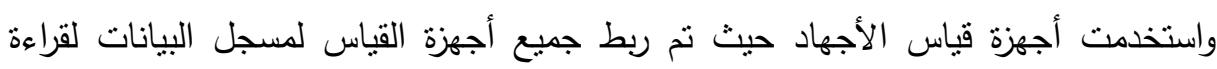
القياسات.

\section{الترواسة المجليلية}

وبعد الأنتهاء من القياسات نم تحليلها وعمل رسومات بيانية، لتربط مابين المتغيرات، ومناقتشة النتائج ومقارنتها واستتباط معادلات لاختيار المعالجة الأكثر فاعلية لتلبية الاحتياجات المطلوبة وذلك للحصول على أفضل هذه الأضافت الخاصة لدولة الكويت. ومن القياسات

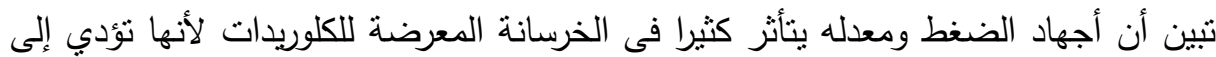
ظهور شروخ شديدة، وبالتالي تتشقق ويقل أجهاد الضغط. ولذا فبعد انتشال العينات وانقضاء الفترة المحددة طبقا لجدول الخطة المعملية تم اختبارها وقياس إجهاد الضغط وتم رسم علاقات

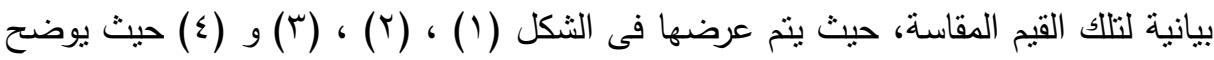
معدل تغير إجهاد الضغط لعينات الغير معالجة و للعينات المعالجة (ببرادة الحديد) والعينات المعالجة (بمادة السيكا) والعينات برقائق الألياف البلاستيكية حيث يتضح أن اجهاد الضغط

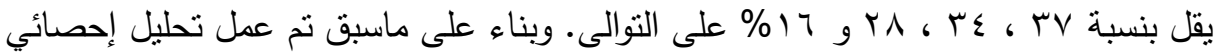

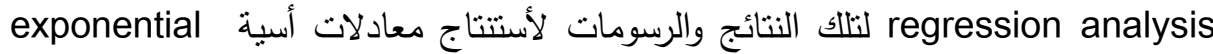
equations

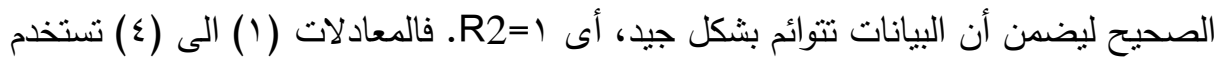

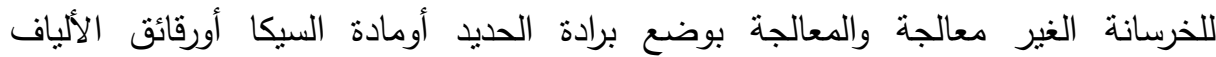

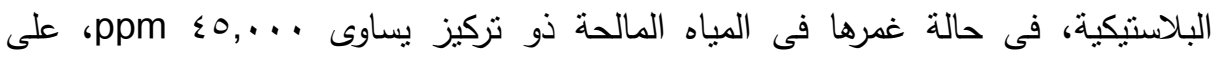
التوالى. حيث t هى الزمن وC: إجهاد الضغط بعد مضى هذا الزمن وe هى على عدد أويلر

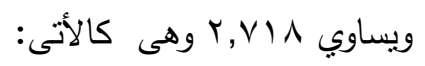

$$
\begin{array}{lll}
C=r r \ldots r e^{-0.018 t} & \text { (1) } & C=r r q, \wedge q \mathrm{e}^{-0.013 t} \\
C=r \backslash \wedge, r r \mathrm{e}^{-0.08 t} & \text { (3) } & C=r \Upsilon \wedge, r q \mathrm{e}^{-0.006 \mathrm{t}}
\end{array}
$$




\section{الاستينماجيه}

وبناء على النتائج التى تم التوصل اليها، تم استتناج أن إجهاد الضغط للعينات تدهور

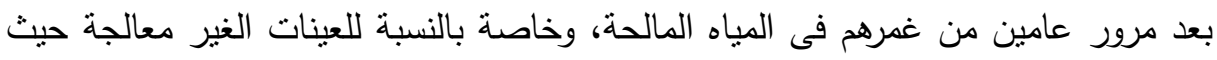
أظهرت تدهورا ملحوظا أما العينات المعالجة (بيرادة الحديد) والعينات المعالجة (بمادة السيكا) فأظهرت تدهورا أقل نسبيا من نظيرتها الغير معالجة. أما العينات المعالجة (برقائق الألياف البلاستنكية) فقد أثتت تحملها لتلك الظروف. وبناء على التحاليل إحصائية ، تم استتباط

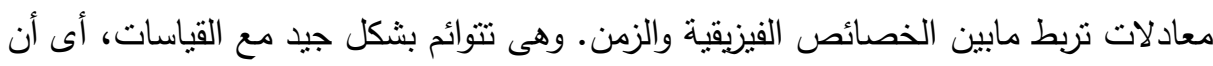

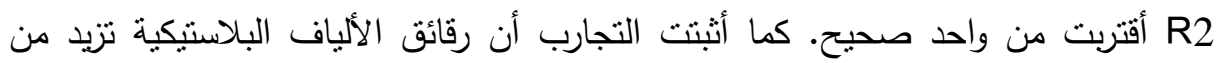

إجهاد الضغط بنسبة كبيرة. جلول(1 ): جدول خصائص العينات عند الاختبار

\begin{tabular}{|c|c|c|c|c|}
\hline زمن الغمر & تركيز المحلول & نوع الخليط & أسم العينة & رقم العينة \\
\hline 1 & \multirow{16}{*}{$\varepsilon 0, \ldots$} & \multirow{4}{*}{ تقليدية } & 1618 & 1 \\
\hline$\Lambda$ & & & $1, \wedge \varepsilon$ & $r$ \\
\hline 17 & & & 16178 & $r$ \\
\hline$T \varepsilon$ & & & $1, Y \leqslant \varepsilon$ & $\varepsilon$ \\
\hline 1 & & \multirow{4}{*}{ برادة الحديد } & $\left.r_{6}\right)_{\varepsilon}$ & 0 \\
\hline$\Lambda$ & & & 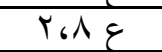 & 7 \\
\hline 17 & & & T.17द & 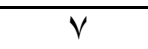 \\
\hline$T \varepsilon$ & & & $T_{6} T \leqslant \varepsilon$ & $\Lambda$ \\
\hline 1 & & \multirow{4}{*}{ السيكا } & $\left.r_{6}\right) \varepsilon$ & 9 \\
\hline$\Lambda$ & & & $\Gamma_{6} \wedge \varepsilon$ & 1. \\
\hline 17 & & & T.17 8 & 11 \\
\hline$T \varepsilon$ & & & $r, T \leqslant \varepsilon$ & IT \\
\hline 1 & & \multirow{4}{*}{ رقائق الألباف } & $\left.\varepsilon_{6}\right) \varepsilon$ & $1 \pi$ \\
\hline$\Lambda$ & & & $\varepsilon_{6} \wedge \varepsilon$ & $1 \varepsilon$ \\
\hline 17 & & & $\varepsilon_{6} 17 \varepsilon$ & 10 \\
\hline$T \xi$ & & & $\varepsilon_{6} r \leqslant \varepsilon$ & 17 \\
\hline
\end{tabular}


مجلة العلوم البيئية

معهد الدراسات والبحوث البيئية - جامعة عين شمس لهن

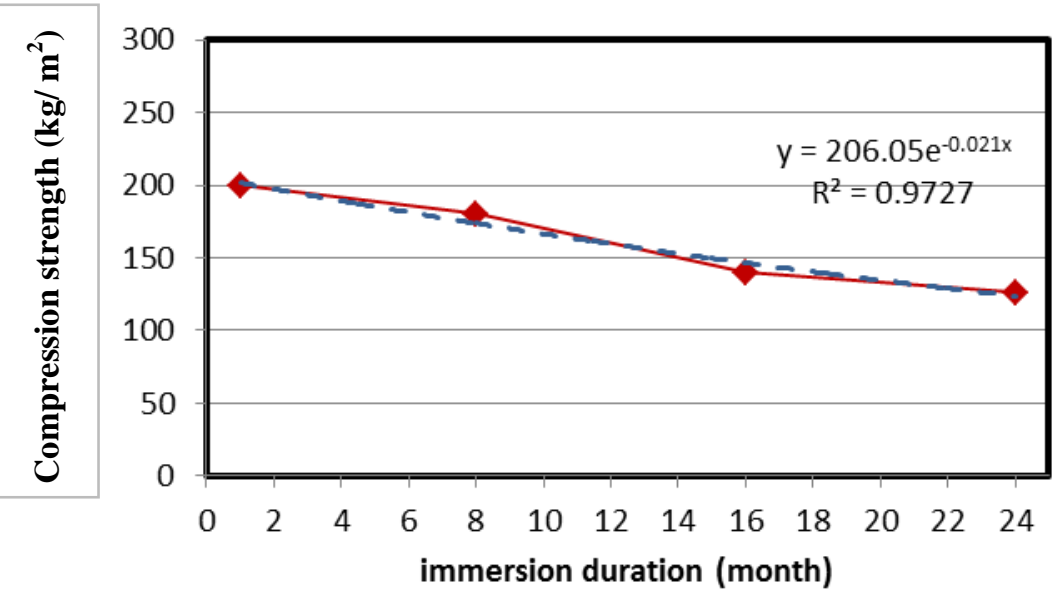

شكل(1) : إجهاد الضغط للعينات الغير معالجة

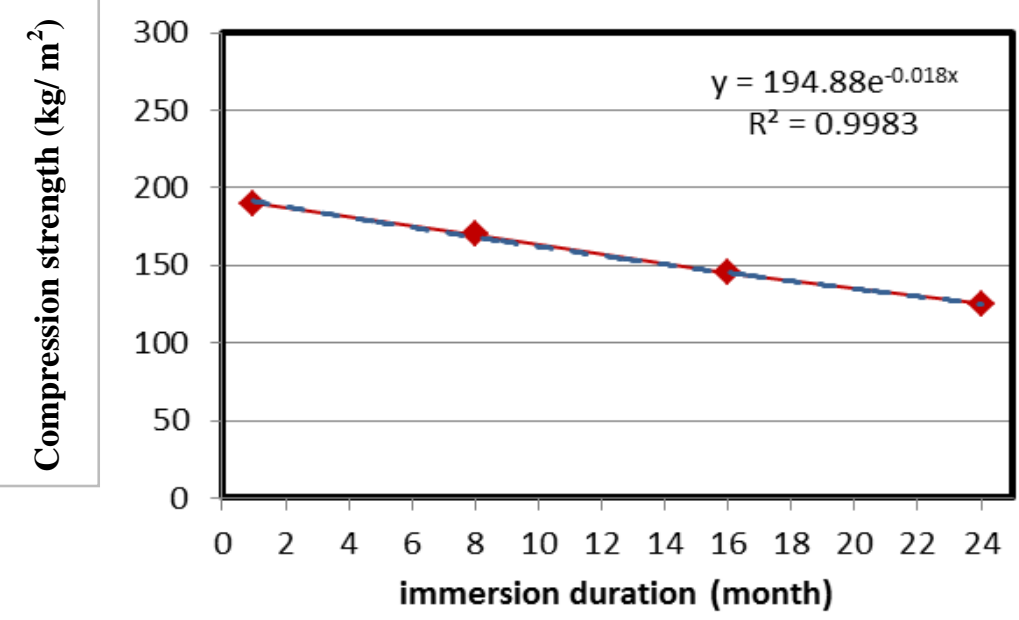

شكل(ץ): إجهاد الضغط للعينات بعد أضافة برادة الحديد 
سونيا الصيرفى وآخرون

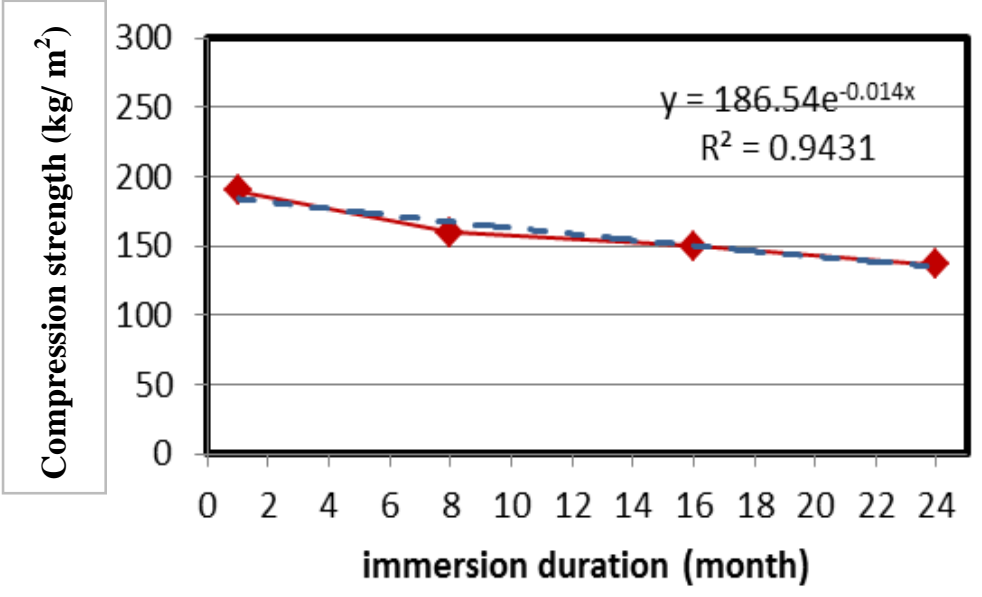

شكل(r): إجهاد الضغط للعينات بعد أضافة السيكا

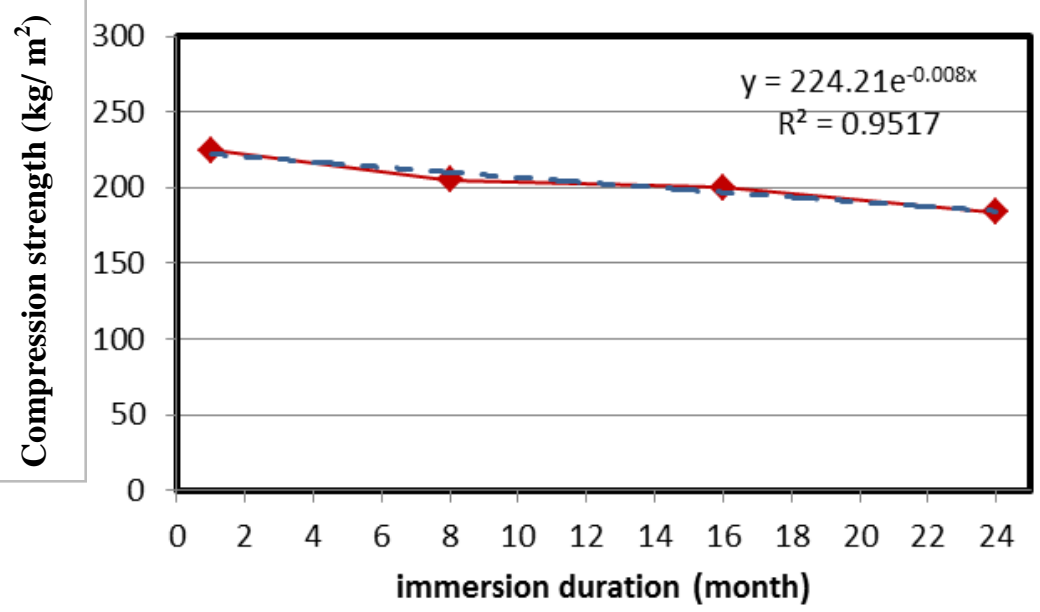

شكل(ع): معدل تغير إجهاد الضغط بعد أضافة رقائق الألياف البلاستيكية

\section{الموكياهي}

وبناء على الاستتاجات السابقة فقد أوصت الدراسة بالأشادات الأتية: بخصوص

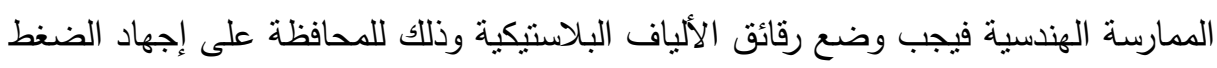


للمنشأت البحرية. كما أوصت باستخدام المعادلات المستتبطة للتتبؤ بالخصائص الفيزيقية وذللك لأنها تتوائم بشكل جيد مع القياسات، حيث أن R2 أقتربت من الواحد الصحيح. أما

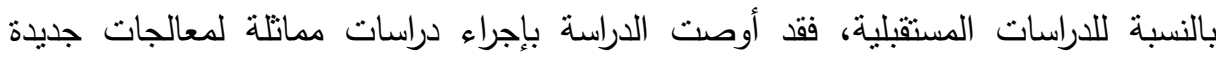
مبتكرة أو بدمج المعالجات مثل السيكا ورقائق الألياف البلاستيكية وذللك لتحسين إجهاد

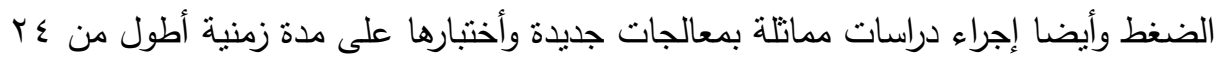

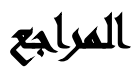

El-Serafy, S. et al. (2017 a). Enhancing the Concrete Behavior Exposed to Chlorides in Tunnels, IJCSE.

El-Serafy, S. et al. (2017 b). Improving Concrete Characteristics Exposed to Chlorides in Coastal Zones, IJCSE.

Tarek Rady et al. (2017) Increasing the lifespan of coastal concrete structures in low-lying lands in Egypt (Nile Delta), unpublished Ph.D thesis, submitted to Ain Shams University. 
سونيا الصيرفى وآخرون

\title{
EFFECT OF ENVIRONMENTAL ADDITIVES ON PRESSURE RESISTANCE OF MARINE STRUCTURES IN KUWAIT
}

\begin{abstract}
Al-Sirafi1, Sonya ${ }^{(1)}$; Al-Enzi, Kh. ${ }^{(1)}$ and Al-Subaie, S. 1) Department of Coastal Engineering, Faculty of Engineering, Ain Shams University 2) Department of Chemistry, Faculty of Science and Technology, Kuwai.
\end{abstract}

\begin{abstract}
In terms of importance of coastal structures in Kuwait, the study was started to investigate compressive strength. A review to previous studies was achieved. Environmental additives were proposed, 16 samples were prepared and immersed in 45.000 ppm salty water for 24 months. Tests and measurements were executed after 8 months intervals. Diagrams were plotted to relate the investigated parameters and statistical analysis was achieved. Plastic fiber sheets were found to achieve the best results. Recommendtins for practice, such as implementig plastic sheets, were suggested. Recommendations for research, innovating other additives, were suggested.
\end{abstract}

Keywords: Environmental additives, pressure resistance, marine structures, Kuwait 